\title{
A study of the effect of training pregnant women about attachment skills on infants' motor development indices at birth to four months
}

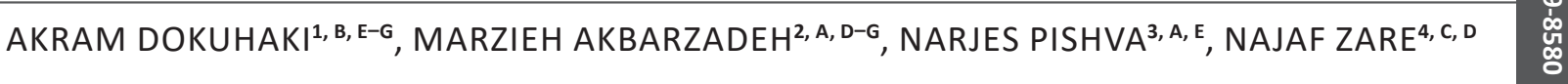

${ }^{1}$ Department of Midwifery, School of Nursing and Midwifery, Shiraz University of Medical Sciences, Shiraz, Iran

${ }^{2}$ Maternal - Fetal Medicine Research Center, Department of Midwifery, School of Nursing and Midwifery, Shiraz University of Medical Sciences, Shiraz, Iran

${ }^{3}$ Department Neonatology, School of Medicin, Neonatal Research Center, Shiraz University of Medical Science, Shiraz, Iran

${ }^{4}$ Department of Biostatistics, Medical School, Infertility Research Center, Shiraz University of Medical Sciences, Shiraz, Iran

A - Study Design, B - Data Collection, C - Statistical Analysis, D - Data Interpretation, E - Manuscript Preparation, F - Literature Search, G - Funds Collection

Summary Background. During pregnancy fetus-maternal attachment can improve maternal-fetal attachment, and have positive effects on the infant's growth and development.

Objectives. This study aimed to investigate the effect of training pregnant mothers about attachment skills on infants' motor development indices at birth to four months.

Material and methods. This study is a clinical trial with convenient sampling on 190 pregnant women in Hafez hospital. They were randomly divided into two groups: intervention and control. There were 94 and 96 patients in the control and intervention groups, respectively. In the intervention group, 6 sessions of 90 -minute educational classes were held. After birth, the infants were compared, in both groups, in terms of motor status using the Denver questionnaire at birth to the age of 4 months.

Results. In the intervention group, educating the women on fetal-maternal attachment skills was associated with infants' earlier achievement age in terms of some gross motor, all fields of speech-language, and one item of fine-adaptive motor realms. In addition, the infants' age was significantly reduced in achieving some personal-social items, as well as gross-fine scope at one and three months. Conclusions. Training the mothers in attachment skills increased fetal-maternal attachment and improved the motor development indicators in infants aged up to four months. Therefore, training in attachment skills is recommended to be given as a component of routine pregnancy care.

Key words: attachment, skills, infant, motor development.

Dokuhaki A, Akbarzadeh M, Pishva N, Zare N. A study of the effect of training pregnant women about attachment skills on infants' motor development indices at birth to four months. Fam Med Prim Care Rev 2017; 19(2): 114-122, doi: https://doi.org/10.5114/ fmpcr.2017.67864.

\section{Background}

Attachment behavior plays an important role in parental identity acceptance, the link between the infants' future and parents', and the baby's growth and development, which should be taught [1].

According to "A Literature Update on Maternal-Fetal Attachment" by Jeanne, maternal-fetal attachment starts long before birth, when the mother begins to form her infant image and evolves interest in her support mentally. In other words, the attachment starts at the 10th week of gestational age, and it reaches its peak at the 16th week [2]. In addition, several studies have proven the efficacy of some exercises in raising the attachment rate during pregnancy. These excercises include spending time talking to the baby during pregnancy, abdominal massage, and counting fetal movement [3-5].

On the other hand, the effect of maternal-fetal attachment on the baby's health, growth, development, and health related indicators has recently attracted researchers' attention. Experts believe in the importance of physical and mental health to provide a better future in babies and children [6].

According to Alhusen et al. a high level of maternal attachment can improve fetal and infant growth after birth. Moreover, the fetus will achieve better growth than others. In this study, mothers with higher levels of prenatal attachment turned out to be more responsible, sensitive and committed than mothers with less fetal attachment [7]. Maternal attachment may lead to increased IQ in infants, and they are more engaged with objects at 9 months of age [8]. During pregnancy, the mother's stress and negative experiences lead to negative effects on infants' physical, motor-behavioral and psychological developments [9]. According to Alhusen et al., the increase of attachment and health level, for one unit, leads to a reduction in adverse neonatal outcomes for $9 \%$ [10]. Brumariu believes that a poor relationship with mothers during utero and the early years of life is associated with more personality disorders, social conflict, and intelligence failure in adolescence [11]. The maternal-fetal bond is based on emotional attachment with a biological foundation $[12,13]$.

Considering that mothers and children constitute two vulnerable groups in society, and given that in developing countries there is low physical and developmental growth and high mortality in infants, it is a major issue requiring special attention. Nonetheless, a limited number of studies have been conducted on the effects of training attachment skills and infant's 
motor development outcomes. Thus, the present study aims to study of the effect of training pregnant women about attachment skills on infants' motor development indices at birth to four months. The expected outcomes are:

Primary outcome: the effects of training attachment skills on the motor development index (gross motor, speech and language, and Fine-adaptive domains at one and three months).

Secondary outcome: Training the mothers in attachment skills; the fetal-maternal attachment level.

\section{Material and methods}

\section{Study design and population}

Training in attachment behavior (the intervention) was conducted during 7 sessions in this clinical trial. Then, the infants in both groups were compared in terms of motor development. The study population included low-risk pregnant women aged 18-40 years within 28-34 weeks of gestational age referred to Hafez hospital.

The sample size was determined according to the formula (comparing the average with a fixed number)

$$
\begin{aligned}
& \mathrm{n}=\frac{2\left(\mathrm{z}_{1-\frac{\alpha}{2}}+\mathrm{z}_{1-\beta}\right)^{2} \sigma^{2}}{\mathrm{~d}^{2}} \\
& d=2 \alpha \\
& \alpha=0.05 \\
& \beta=80 \%
\end{aligned}
$$

In addition, $10 \%$ was considered as a sample loss. Finally, the sample size was calculated as 99 for each group. The sampling method was a simple purposive one. After sample selection, the random block method was applied to divide them into control and intervention groups. The number of patients increased both equally and gradually (Figure 1 ).

\section{Inclusion and exclusion criteria}

Inclusion criteria included pregnant women aged 18 to 40 with gestational age of 28-34 weeks, married, Shiraz residency, planned pregnancy, singleton, third grade of middle school as the minimum literacy, low-risk pregnancy with low and medium level of anxiety based on the Spielberger anxiety Inventory who agreed to participate in the study. Exclusion criteria were mother's absence (in the training classes) of more than one session, pregnancy losses, problems that put pregnancies in conditions of high-risk, lack of physical health in infants, and congenital malformations.

\section{Intervention}

In the intervention group, 6 sessions of 90-minute educational classes were held. Teaching techniques were questions and answers, detailed clarification by the teacher, lectures, discussions, watching videos, and role playing by the participants. The topics taught were: knowledge of pregnancy, awareness of embryonic feelings and perceptions, fetal attachment and how to communicate with it, controling anxiety and negative thoughts, embryo and infant perceptions and mental imagery, relaxation exercises, proper sleep patterns, exercise, and nutrition.

\section{Enrollment}

Assessed for eligibility $(n=267)$

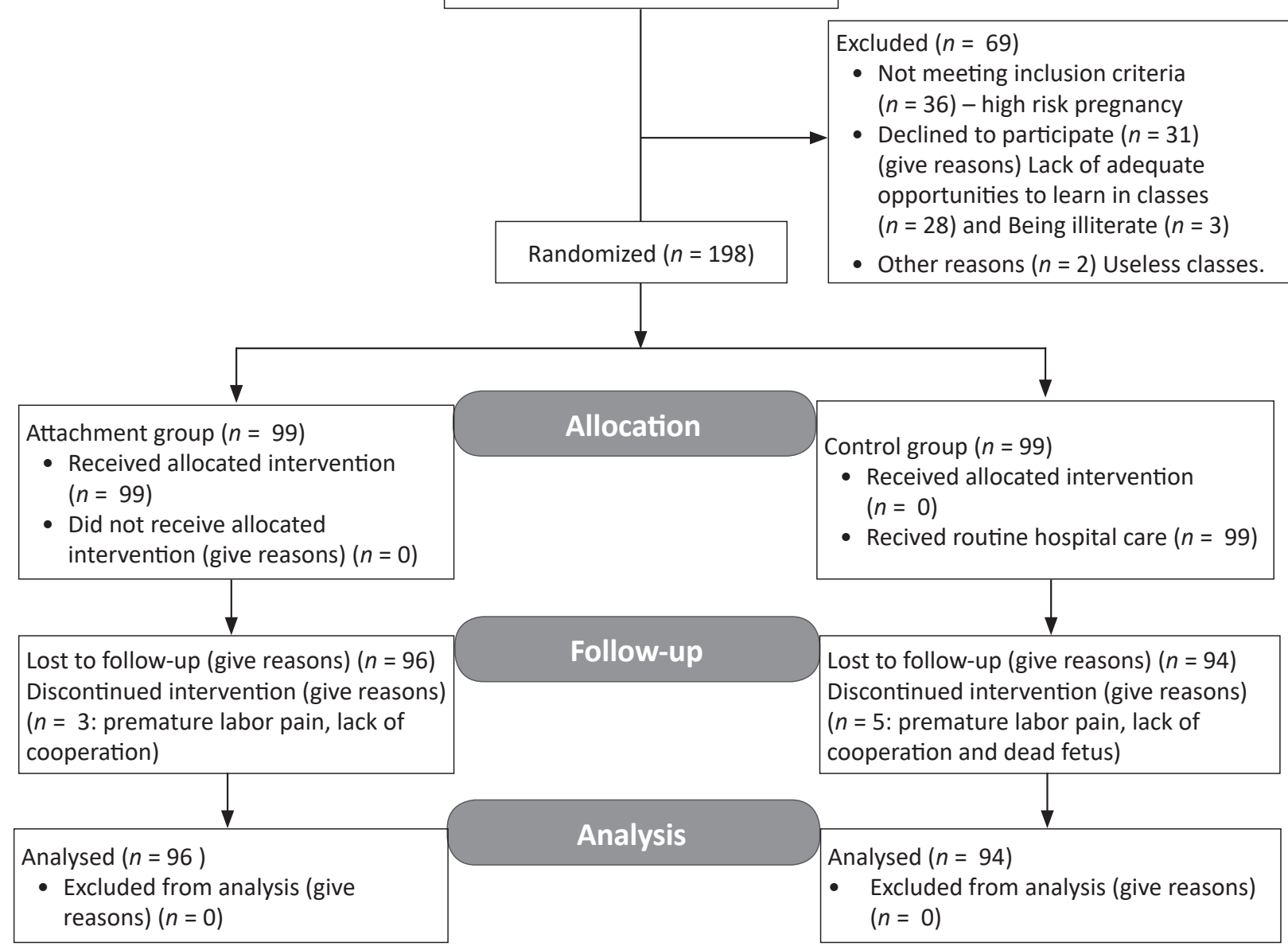

Figure 1. Flow diagram of sampling 
The pregnancy food pyramid diet was advised, so that for each of the food groups: bread and grains, fruits and vegetables, meat and beans, dairy products, and miscellaneous, the number of specified unit to arrange 2,3,2,5,3 was advised, so fat intake to $30 \%$ and additional sugar was allowed up to $25 \%$ of total energy [14].

\begin{tabular}{|c|c|c|c|c|}
\hline \multirow[t]{3}{*}{ Gross motor domain } & \multirow[t]{3}{*}{ Sex } & \multicolumn{2}{|l|}{ Groups } & \multirow[t]{3}{*}{$p$} \\
\hline & & Control & Intervention & \\
\hline & & Mean \pm standard deviation & Mean \pm standard deviation & \\
\hline \multirow[t]{3}{*}{ 1. Equal hand movement } & Male & $0.35 \pm 0.12$ & $0.52 \pm 0.23$ & $<0.001$ \\
\hline & Female & $0.19 \pm 0.14$ & $0.17 \pm 0.11$ & 0.446 \\
\hline & Total & $0.36 \pm 0.25$ & $0.27 \pm 0.15$ & 0.079 \\
\hline \multirow[t]{3}{*}{ 2. Equal hand usage } & Male & $0.62 \pm 0.19$ & $0.57 \pm 0.29$ & 0.008 \\
\hline & Female & $0.55 \pm 0.28$ & $0.46 \pm 0.15$ & 0.171 \\
\hline & Total & $0.58 \pm 0.24$ & $0.52 \pm 0.24$ & 0.006 \\
\hline \multirow[t]{3}{*}{ 3. Equal foot movement } & Male & $0.58 \pm 0.20$ & $0.50 \pm 0.17$ & 0.027 \\
\hline & Female & $0.47 \pm 0.23$ & $0.45 \pm 0.24$ & 0.558 \\
\hline & Total & $0.52 \pm 0.22$ & $0.48 \pm 0.21$ & 0.058 \\
\hline \multirow{3}{*}{$\begin{array}{l}\text { 4. Hold head steady for } 5-4 \text { finger size } \\
\text { when held in prone position }\end{array}$} & Male & $1.74 \pm 0.63$ & $1.55 \pm 0.53$ & 0.107 \\
\hline & Female & $1.67 \pm 0.58$ & $1.54 \pm 0.55$ & 0.299 \\
\hline & Total & $1.71 \pm 0.61$ & $1.55 \pm 0.54$ & 0.059 \\
\hline \multirow{3}{*}{$\begin{array}{l}\text { 5. Head elevation and looking around } \\
\text { in prone position }\end{array}$} & Male & $2.39 \pm 0.51$ & $2.15 \pm 0.54$ & 0.026 \\
\hline & Female & $2.30 \pm 0.49$ & $2.32 \pm 0.55$ & 0.856 \\
\hline & Total & $2.35 \pm 0.50$ & $2.23 \pm 0.55$ & 0.130 \\
\hline \multirow{3}{*}{$\begin{array}{l}\text { 6. Be able to hold head when held in } \\
\text { sitting position (in mother's arms) }\end{array}$} & Male & $3.82 \pm 0.33$ & $3.73 \pm 0.23$ & 0.132 \\
\hline & Female & $3.73 \pm 0.31$ & $3.72 \pm 0.26$ & 0.922 \\
\hline & Total & $3.77 \pm 0.32$ & $3.73 \pm 0.24$ & 0.262 \\
\hline \multirow[t]{3}{*}{ 7. Hand leaning in the prone position } & Male & $3.97 \pm 0.31$ & $3.87 \pm 0.22$ & 0.077 \\
\hline & Female & $3.96 \pm 0.30$ & $3.91 \pm 0.22$ & 0.399 \\
\hline & Total & $3.96 \pm 0.30$ & $3.89 \pm 0.22$ & 0.234 \\
\hline \multirow[t]{3}{*}{ 8. Foot standing with mother's support } & Male & $3.50 \pm 0.30$ & $3.27 \pm 0.24$ & $<0.001$ \\
\hline & Female & $3.29 \pm 0.31$ & $3.29 \pm 0.30$ & 0.316 \\
\hline & Total & $3.40 \pm 0.32$ & $3.28 \pm 0.27$ & 0.001 \\
\hline \multirow{3}{*}{$\begin{array}{l}\text { 9. Head control while changing posi- } \\
\text { tion from lying into sitting }\end{array}$} & Male & $4.11 \pm 0.33$ & $3.92 \pm 0.25$ & 0.002 \\
\hline & Female & $4.01 \pm 0.30$ & $4.01 \pm 0.36$ & 0.958 \\
\hline & Total & $4.06 \pm 0.32$ & $3.96 \pm 0.31$ & 0.033 \\
\hline
\end{tabular}

\begin{tabular}{|c|c|c|c|c|}
\hline \multirow[t]{3}{*}{ Speech and language domain } & \multirow[t]{3}{*}{ Sex } & \multicolumn{2}{|l|}{ Groups } & \multirow[t]{3}{*}{$p$} \\
\hline & & Control & Intervention & \\
\hline & & Mean \pm standard deviation & Mean \pm standard deviation & \\
\hline \multirow{3}{*}{$\begin{array}{l}\text { 1. Turning head toward sounds and } \\
\text { voices }\end{array}$} & Male & $0.56 \pm 0.30$ & $0.29 \pm 0.18$ & $<0.001$ \\
\hline & Female & $0.41 \pm 0.31$ & $0.40 \pm 0.21$ & 0.911 \\
\hline & Total & $0.49 \pm 0.32$ & $0.34 \pm 0.20$ & 0.003 \\
\hline \multirow{3}{*}{$\begin{array}{l}\text { 2. Making "cooing" sounds like: A, } \\
\text { wow }\end{array}$} & Male & $1.44 \pm 0.39$ & $1.17 \pm 0.34$ & $<0.001$ \\
\hline & Female & $1.31 \pm 0.26$ & $1.22 \pm 0.33$ & 0.155 \\
\hline & Total & $1.38 \pm 0.34$ & $1.19 \pm 0.33$ & $<0.001$ \\
\hline \multirow[t]{3}{*}{ 3. Making gurgling sounds } & Male & $2.75 \pm 0.36$ & $2.54 \pm 0.35$ & 0.003 \\
\hline & Female & $2.64 \pm 0.27$ & $2.56 \pm 0.31$ & 0.188 \\
\hline & Total & $2.69 \pm 0.32$ & $2.55 \pm 0.33$ & 0.001 \\
\hline \multirow[t]{3}{*}{ 4. Laughing out loud } & Male & $2.09 \pm 0.40$ & $1.84 \pm 0.35$ & 0.001 \\
\hline & Female & $1.98 \pm 0.28$ & $1.91 \pm 0.36$ & 0.088 \\
\hline & Total & $2.04 \pm 0.35$ & $1.87 \pm 0.35$ & $<0.001$ \\
\hline \multirow[t]{3}{*}{ 5. Screaming } & Male & $2.91 \pm 0.36$ & $2.67 \pm 0.32$ & 0.001 \\
\hline & Female & $2.80 \pm 0.28$ & $2.70 \pm 0.29$ & 0.096 \\
\hline & Total & $2.85 \pm 0.33$ & $2.68 \pm 0.31$ & $<0.001$ \\
\hline
\end{tabular}




\begin{tabular}{|c|c|c|c|c|}
\hline \multirow[t]{3}{*}{ Fine-adaptive domain } & \multirow[t]{3}{*}{ Sex } & \multicolumn{2}{|l|}{ Groups } & \multirow[t]{3}{*}{$p$} \\
\hline & & Control & Intervention & \\
\hline & & Mean \pm standard deviation & Mean \pm standard deviation & \\
\hline \multirow{3}{*}{$\begin{array}{l}\text { 1. Following an object in the middle } \\
\text { line }\end{array}$} & Male & $0.59 \pm 0.18$ & $0.49 \pm 0.11$ & 0.002 \\
\hline & Female & $0.60 \pm 0.15$ & $0.51 \pm 0.16$ & 0.005 \\
\hline & Total & $0.60 \pm 0.17$ & $0.50 \pm 0.13$ & $<0.001$ \\
\hline \multirow{3}{*}{$\begin{array}{l}\text { 2. Following an object outside the } \\
\text { middle line }\end{array}$} & Male & $1.68 \pm 0.19$ & $1.68 \pm 0.19$ & 0.857 \\
\hline & Female & $1.74 \pm 0.27$ & $1.70 \pm 0.16$ & 0.491 \\
\hline & Total & $1.71 \pm 0.23$ & $1.69 \pm 0.17$ & 0.677 \\
\hline \multirow[t]{3}{*}{ 3. Holding rattles by hand } & Male & $3.34 \pm 0.51$ & $3.12 \pm 0.49$ & 0.032 \\
\hline & Female & $3.29 \pm 0.48$ & $3.27 \pm 0.52$ & 0.842 \\
\hline & Total & $3.31 \pm 0.49$ & $3.19 \pm 0.51$ & 0.088 \\
\hline \multirow{3}{*}{$\begin{array}{l}\text { 4. Hands reaching while lying on the } \\
\text { back }\end{array}$} & Male & $3.17 \pm 0.19$ & $3.15 \pm 0.25$ & 0.305 \\
\hline & Female & $3.21 \pm 0.19$ & $3.10 \pm 0.38$ & 0.311 \\
\hline & Total & $3.19 \pm 0.19$ & $3.12 \pm 0.31$ & 0.155 \\
\hline \multirow{3}{*}{$\begin{array}{l}\text { 5. Head turning from side to side with } \\
\text { a flick of the object in front of them }\end{array}$} & Male & $3.68 \pm 0.16$ & $3.67 \pm 0.21$ & 0.938 \\
\hline & Female & $3.71 \pm 0.19$ & $3.64 \pm 0.17$ & 0.113 \\
\hline & Total & $3.69 \pm 0.17$ & $3.66 \pm 0.19$ & 0.250 \\
\hline
\end{tabular}

\begin{tabular}{|c|c|c|c|c|}
\hline \multirow[t]{3}{*}{ Personal-social domains } & \multirow[t]{3}{*}{ Sex } & \multicolumn{2}{|l|}{ Groups } & \multirow[t]{3}{*}{$p$} \\
\hline & & Control & Intervention & \\
\hline & & Mean \pm standard deviation & Mean \pm standard deviation & \\
\hline \multirow[t]{3}{*}{ 1. Face staring } & Male & $0.65 \pm 0.18$ & $0.56 \pm 0.19$ & 0.011 \\
\hline & Female & $0.64 \pm 0.17$ & $0.61 \pm 0.17$ & 0.339 \\
\hline & Total & $0.64 \pm 0.17$ & $0.58 \pm 0.18$ & 0.011 \\
\hline \multirow[t]{3}{*}{ 2. Smiling with awakeness } & Male & $1.29 \pm 0.22$ & $1.21 \pm 0.19$ & 0.083 \\
\hline & Female & $1.35 \pm 0.30$ & $1.22 \pm 0.16$ & 0.009 \\
\hline & Total & $1.32 \pm 0.26$ & $1.21 \pm 0.17$ & 0.002 \\
\hline \multirow{3}{*}{$\begin{array}{l}\text { 3. Smiling and touching or talking with } \\
\text { them }\end{array}$} & Male & $1.40 \pm 0.20$ & $1.40 \pm 0.24$ & 0.972 \\
\hline & Female & $1.45 \pm 0.24$ & $1.39 \pm 0.29$ & 0.217 \\
\hline & Total & $1.43 \pm 0.22$ & $1.40 \pm 0.22$ & 0.420 \\
\hline \multirow[t]{3}{*}{ 4. Staring at hands } & Male & $2.50 \pm 0.28$ & $2.44 \pm 0.38$ & 0.638 \\
\hline & Female & $2.53 \pm 0.32$ & $2.49 \pm 0.26$ & 0.775 \\
\hline & Total & $2.51 \pm 0.30$ & $2.46 \pm 0.33$ & 0.893 \\
\hline
\end{tabular}

\begin{tabular}{|c|c|c|c|c|}
\hline \multirow[t]{3}{*}{ Fine-gross movements at 1 months } & \multirow[t]{3}{*}{ Sex } & \multicolumn{2}{|l|}{ Groups } & \multirow[t]{3}{*}{$p$} \\
\hline & & Control & Intervention & \\
\hline & & Mean \pm standard deviation & Mean \pm standard deviation & \\
\hline \multirow[t]{3}{*}{ 1. Body bending in the prone position } & Male & $0.98 \pm 0.20$ & $0.89 \pm 0.16$ & 0.023 \\
\hline & Female & $0.95 \pm 0.22$ & $0.90 \pm 0.20$ & 0.263 \\
\hline & Total & $0.96 \pm 0.21$ & $0.89 \pm 0.18$ & 0.019 \\
\hline \multirow{3}{*}{$\begin{array}{l}\text { 2. Turning and head elevation in the } \\
\text { prone position }\end{array}$} & Male & $1.01 \pm 0.24$ & $0.95 \pm 0.17$ & 0.377 \\
\hline & Female & $1.01 \pm 0.20$ & $0.95 \pm 0.22$ & 0.207 \\
\hline & Total & $1.01 \pm 0.22$ & $0.95 \pm 0.19$ & 0.074 \\
\hline \multirow{3}{*}{$\begin{array}{l}\text { 3. Head holding tangent to the body in } \\
\text { the hanging and prone position }\end{array}$} & Male & $1.02 \pm 0.28$ & $1.01 \pm 0.25$ & 0.900 \\
\hline & Female & $1.05 \pm 0.22$ & $0.97 \pm 0.23$ & 0.113 \\
\hline & Total & $1.03 \pm 0.25$ & $0.99 \pm 0.24$ & 0.150 \\
\hline \multirow{3}{*}{$\begin{array}{l}\text { 4. Round back in the sitting position } \\
\text { without head control }\end{array}$} & Male & $0.81 \pm 0.24$ & $0.75 \pm 0.17$ & 0.377 \\
\hline & Female & $0.81 \pm 0.20$ & $0.75 \pm 0.22$ & 0.207 \\
\hline & Total & $0.81 \pm 0.22$ & $0.75 \pm 0.19$ & 0.074 \\
\hline
\end{tabular}




\begin{tabular}{|c|c|c|c|c|}
\hline \multirow[t]{3}{*}{ Fine-gross movements at 1 months } & \multirow[t]{3}{*}{ Sex } & \multicolumn{2}{|l|}{ Groups } & \multirow[t]{3}{*}{$p$} \\
\hline & & Control & Intervention & \\
\hline & & Mean \pm standard deviation & Mean \pm standard deviation & \\
\hline \multirow[t]{3}{*}{ 5. Strong grab reflex } & Male & $0.82 \pm 0.24$ & $0.73 \pm 0.14$ & 0.086 \\
\hline & Female & $0.78 \pm 0.14$ & $0.78 \pm 0.13$ & 0.604 \\
\hline & Total & $0.80 \pm 0.19$ & $0.75 \pm 0.14$ & 0.097 \\
\hline \multirow[t]{3}{*}{ 6. Hand grip in contact with rattles } & Male & $1.02 \pm 0.24$ & $0.93 \pm 0.14$ & 0.086 \\
\hline & Female & $0.98 \pm 0.14$ & $0.96 \pm 0.13$ & 0.604 \\
\hline & Total & $1.00 \pm 0.19$ & $0.95 \pm 0.13$ & 0.097 \\
\hline
\end{tabular}

\begin{tabular}{|c|c|c|c|c|}
\hline \multirow{3}{*}{$\begin{array}{l}\text { Fine-gross movement at three } \\
\text { months }\end{array}$} & \multirow[t]{3}{*}{ Sex } & \multicolumn{2}{|l|}{ Groups } & \multirow[t]{3}{*}{$p$} \\
\hline & & Control & Intervention & \\
\hline & & Mean \pm standard deviation & Mean \pm standard deviation & \\
\hline \multirow{3}{*}{$\begin{array}{l}\text { 1. Holding head steady when held in } \\
\text { the sitting position }\end{array}$} & Male & $3.02 \pm 0.21$ & $2.75 \pm 0.21$ & $<0.001$ \\
\hline & Female & $3.05 \pm 0.27$ & $2.94 \pm 0.21$ & 0.041 \\
\hline & Total & $3.03 \pm 0.24$ & $2.84 \pm 0.23$ & $<0.001$ \\
\hline \multirow[t]{3}{*}{ 2. Head elevation with delay } & Male & $2.77 \pm 0.24$ & $2.76 \pm 0.23$ & 0.739 \\
\hline & Female & $2.83 \pm 0.25$ & $2.77 \pm 0.21$ & 0.254 \\
\hline & Total & $2.80 \pm 0.25$ & $2.76 \pm 0.22$ & 0.294 \\
\hline \multirow{3}{*}{$\begin{array}{l}\text { 3. Lifts head and shoulders off the } \\
\text { floor at } 45 \text { to } 60 \text { degrees when lying } \\
\text { on the back }\end{array}$} & Male & $2.39 \pm 0.51$ & $2.15 \pm 0.54$ & 0.026 \\
\hline & Female & $2.30 \pm 0.49$ & $2.30 \pm 0.44$ & 0.999 \\
\hline & Total & $2.35 \pm 0.50$ & $2.22 \pm 0.55$ & 0.102 \\
\hline \multirow{3}{*}{$\begin{array}{l}\text { 4. Hand care and support weight with } \\
\text { legs on standing }\end{array}$} & Male & $3.05 \pm 0.24$ & $3.00 \pm 0.19$ & 0.270 \\
\hline & Female & $3.04 \pm 0.23$ & $3.00 \pm 0.18$ & 0.405 \\
\hline & Total & $3.05 \pm 0.23$ & $3.00 \pm 0.18$ & 0.474 \\
\hline \multirow[t]{3}{*}{ 5. Active holding rattle with hands } & Male & $2.80 \pm 0.18$ & $2.79 \pm 0.19$ & 0.977 \\
\hline & Female & $2.85 \pm 0.19$ & $2.78 \pm 0.20$ & 0.058 \\
\hline & Total & $2.83 \pm 0.18$ & $2.78 \pm 0.19$ & 0.167 \\
\hline \multirow{3}{*}{$\begin{array}{l}\text { 6. The ability to reach and grab blan- } \\
\text { ket and clothes }\end{array}$} & Male & $3.00 \pm 0.18$ & $2.99 \pm 0.19$ & 0.678 \\
\hline & Female & $3.05 \pm 0.19$ & $2.96 \pm 0.19$ & 0.022 \\
\hline & Total & $3.03 \pm 0.18$ & $2.97 \pm 0.19$ & 0.056 \\
\hline
\end{tabular}

To encourage pregnant mothers, they were encouraged to talk about the benefits of exercise in pregnancy, such as: cardiovascular Fitness, muscular strength and endurance, healthy body weight, improved posture, and the prevention or treatment of complications of pregnancy $[15,16]$.

Gentle exercise with more emphasis on walking, low-impact aerobics and stretching exercises was advised. It was stressed that exercise in the supine position should not be prolonged, and so regular, half an hour daily exercise, with gradually increased intensity and duration was advised [16] (Figure 2).

Mothers in the control group also benefited from the routine care training during pregnancy, except for the education with regard to attachment promotion.

\section{Measuring tools}

Data collection tools included a personal information form (demographic and reproductive characteristics, previous pregnancy outcomes, etc.), which was completed before the intervention, the Spielberger questionnaire, which was completed before and after the intervention by mothers, and the 2-Denver motor development index. This questionnaire was compeleted by mothers at the time of birth to 4 months of age. The Spielberger scale was used to assess anxiety. It comprises 40 items with 80 scores. Trait Anxiety (A-Trait) and State Anxiety (A-State) scales comprise 20 items each, scored on a 4-point Likert-type response scale. The reliability and validity of the present study have been reported good by Aghamohammadiyan et al. [17].

The main criterion to measure the infants' motor developement was done thorough screening with the Denver Developmental Screening Test (DDST), which was set for infants up to 4 months of age. This questionnaire contains different aspects of evaluation such as gross motor development by 9 questions: vibropressing of both hands, equally moving arms and legs, holding the head steady for 5-4 finger size when held in the prone position, head elevation and looking around in the prone position, being able to hold the head when held in a sitting position (in the mother's arms), hand leaning in the prone position, foot standing, and head control while changing position from lying into sitting. Speech-language skills include six questions, i.e. turning the head toward sounds and voices, making "cooing" sounds like: A, wow, gurgling sounds, laughing out loud, screaming, and looking at a rattles while it sounds. Fine-adaptive motor skills include five questions: following an object in the middle line, following an object outside the middle line, holding rattles by hand, hands reaching while lying on the back, head turning from side to side with a flick of the object in front of them. There are 5 personal-social questions: face staring, smiling while awake, smiling and touching or talking with themm, and staring at hands. The 6 questions on fine-gross motor developement 

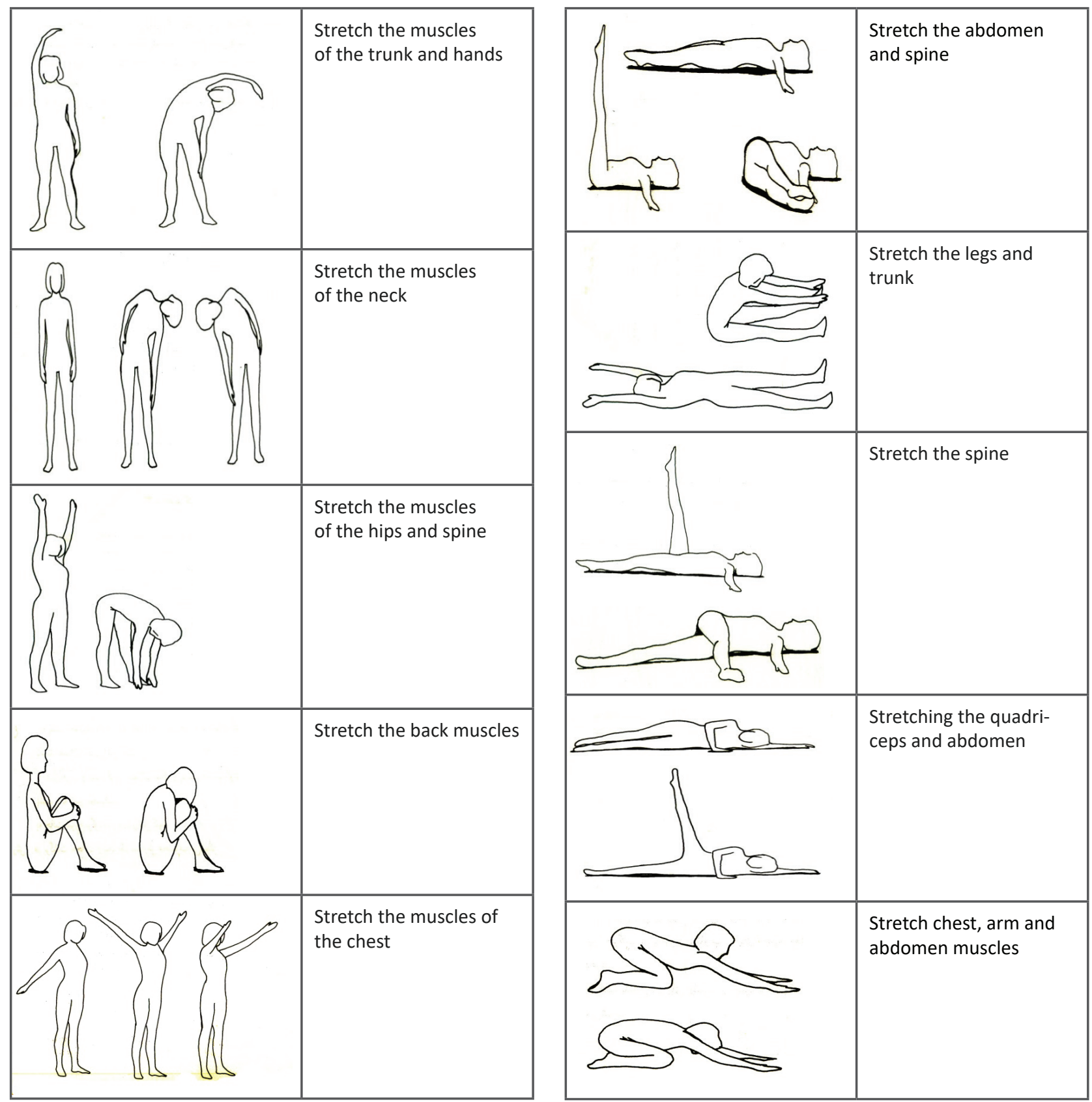

Figure 2. Simple stretching exercises during pregnancy

Source: Albarzadeh M, Alizadeh L. Menopause consulting. Publishers: Iran Shiraz-Karim Khan; 2007: 164-167.

(at one month of age) comprise body bending in the prone position, turning and head elevation in the prone position, head holding tangent to the body in the hanging and prone position, round-like position in the sitting position with no head control, strong grab reflex, and hand grip in contact with rattles. The 6 questions on fine-gross movements at 6 months comprise holding the head steady when held in sitting position, head elevation with delay, lifting the head and shoulders off the floor at 45 to 60 degrees, hand focuses, standing when held, bent knees and supporting weight with legs, and the ability to reach and grab a blanket and clothes.

\section{Ethical considerations}

This research project was approved by the local Ethics Committee of Shiraz University of Medical Sciences, and written informed consents were obtained from all the participants. The research proposal is No. 9192-6857. The research in the Iranian Registry of clinical trial has been registered with the registration number: 2014042217393 N1.

\section{Data analysis}

In this test, the achievement age of each child's developmental functions was specified. A significance level of 0.05 was assumed in this test. An independent T-test was applied in the case of normal distribution to compare the average. Otherwise, an equivalent non-parametric test (Mann-Whitney) was applied.

Infants' development index was applied (from time of birth up to 4 months age). It was based on the Denver test that was compeleted by the mothers. Mothers recorded the baby's achievement age at each stage of the development scope. They were taught how to complete the questionnaire beforehand. In this study, patients and researchers (trainer class) were aware of the patients' setting in the control or intervention groups. Howevere, the researchers who examined the babies and the ones who analyzed the data were blind about the patients' group distribution. 


\section{Results}

The mean age of the patients in the intervention and control groups was $28.04 \pm 6.02$ and $27.72 \pm 5.55$ years, respectively.

The most frequent age ranges were in the under 25-age category in the intervention group and between the ages of 25 to 30 years in the control group.

About $79.20 \%(n=76)$ of the mothers in the intervention group and $77.80 \%(n=73)$ in the control group were housewives. The lowest and highest score of anxiety was 6 and 60 in the intrevention group and 3.5 and 60 in the control group, respectively.

Training in the attachment behaviors leads to decreased age of motor development in the infants of the intervention group, particularly in a few cases of gross motor ahievement, such as the equal hand movement $(0.35 \pm 0.12$ control, $0.52 \pm 0.23$ in tervention, $p<0.001$ ), standing with the mother's support ( 3.50 \pm 0.30 control, $3.27 \pm 0.24$ intervention, $p=0.001$ ), and head control in changing positions ( $4.06 \pm 0.32$ control, $3.96 \pm 0.31$ intervention, $p=0.033$ ) (Table 1 ).

Moreover, this difference was statistically significant in all speaking skills and one item of fine-adaptive motor development (object following in the central line $0.60 \pm 0.17$ control, $0.50 \pm 0.13$ intervention, $p<0.001$ ) (Table 2, 3). In addition, this difference was significant in some personal-social items, such as face staring $(0.65 \pm 0.18$ control, $0.56 \pm 0.19$ intervention, $p=0.011)$, smiling in awakeness $(1.32 \pm 0.26$ control, $1.21 \pm 0.17$ intervention, $p=0.002$ ) (Table 4 ) and some items of gross-fine motor functions, such as body bending in the prone position (0.96 \pm 0.21 control, $0.89 \pm 0.18$ intervention, $p=0.019$ ), head holding in the sitting position $p<0.001$ ) at 1 and 3 months of age.

\section{Discussion}

In this study education in attachment skills causes a significant increase in the infants' motor development (in the intervention group). We had a decrease in the infants' age of gross motor development (some activities), speaking skills (all items), and one item of fine-adaptive skill. In addition, this difference was significant in some personal-social items and gross-fine motor functions at 1 and 3 months of age.

Tubach et al. evaluated infants' motor development using the Barent questionnaire at $0-5$ years of age in their study. The results of motor deveopment comparison were not statistically significant in infants [18]. In Tubach's study (in contrast to the present study), the intervention did not cause any motor development in infants. His intervention was regular visits during pregnancy. However, the educational classes were held for expectant mothers in this study.

In fact, Tubach had not attempted to promote maternal attachment during pregnancy, but this study aimed to improve the infants' motor development through the promotion of maternal-fetal attachment. During pregnancy, effective fetal-maternal communication can improve the infant's developmental status. This could be the reason for his findings. Alhusen et al. conducted a study to examine the effect of maternal-fetal attachment and its impact on infant growth and development outcomes. They found that lack of maternal-fetal attachment $(b=0.9795 \% \mathrm{Cl}[0.97-0.98] ; p<0.001)$ and postpartum depression ( $b=0.97 \mathrm{Cl}[0.96-0.99] ; p<0.001)$ are two important predictors for the early development of children in the initial years of growth. During pregnancy, women with lower fetus-attachment, and those with postpartum depression had more developmental delay compared to those with more attachment [7]. Alhusen et al. believes in the impact of maternal-fetal attachment and postpartum depression on the infants' motor development. The present study studied the impact of maternal-fetal attachment skills on infants' motor development. In fact, both studies evaluated the impact of factors on motor develop- ments. Therefore, fetal-maternal attachment has a direct link with infants' development, while postpartum depression has an indirect correlation. Toosi et al. did a study in this regard to disclose the effective impression of training classes to decrease the mothers' anxiety on some neonatal reflexes such as reflexes moro $(p=0.002)$, planter grasp $(p=0.001)$, grasp plamer $(0.01)$, and babinsky (0.001). The sum score was $22.3 \pm 1.8$ and 20.6 \pm 1.6 in the intervention and control groups, respectively. The significance level was 0.001 [19]. In our study, no significant difference was reported concerning the age of motor development such as reflex grab $(p=0.097)$ and head aligning vertically with the body in the hanging position $(p=0.150)$ at 1 month of age between groups. Muluk et al. stated the mother's role, her effective communication with the baby, and socio-economic factors as the most important ones affecting the evolution of Speech-Language skills in the domain of motor development [20]. According to them, the mother's role function, her effective communication with the baby, and socio-economic factors also effect the infant's motor development. The present study stated fetal-maternal behaviours as the most effective factor.

According to the study conducted by Figueiredo et al. on 104 pregnant women, thehe fetuses of non-depressed pregnant women showed higher HR variability than the fetuses of depressed pregnant women in response to speech stimuli, and later as neonates they performed more optimally on the Neonatal Behavioral Assessment Scale (on autonomic stability and total scores) [21]. In this study, the education of attachment skills reduced maternal anxiety and improved motor development in infants. In addition, Bergman et al. conducted a study on the level of cortisol during pregnancy, its correlation with the infant's cognitive development, and its role in maternal-fetal attachment [22].

Fetus-maternal attachment, as a separate factor among prenatal, obstetric, and socio-economic factors, can affect the infant's physical-cognitive abilities. The infant development indicator was associated with anxiety and postpartum depression. Cho et al. reported that stress, anxiety, and increased level of cortisol and testosterone in pregnant mothers can affect the infant's health, the fetal-maternal relationship, language, and motor and cognitive development, especially in boys [23]. In the present study the greatest effect of attachment training was on boys' motor development among the studied infants.

In other words, the mean age of achieving gross motor and speech-language skills was lower in the male infants of the intervention group compared to the control group. Therefore, the effect of maternal-fetal attachment and reduced maternal anxiety was correlated with improved motor development in infants, especially newborn boys.

In addition, O'Connor et al. suggested that there is a strong correlation between maternal anxiety and infants' behavior and cognitive outcomes [24].

In fact, Bergman et al. come to the conclusion that maternal mood and her cortisol level during pregnancy affect the infant's growth and motor development [18]. Alidustishahraki et al. stated that training classes and developmental skill sessions have no effect on the evolutionary progress of childrenaged at 7-5 months. Alidustishahraki et al. found no correlation between the infants' motor development and their intervention, which was in contrast to our results. The intervention was in the form of educational class for pregnant mothers, and no iformation was offered about attachment behaviors [25]. According to the study conducted by Burchinal et al., the quality of care directly affects the progress of language-cognitive skills [26]. In this study, we also found a correlation between education and accelerated age of achieving maturity indicators, mostly in the field of speech-language and personal-social realms. The difference was significant in the level of significance, $(p<0.001$ and $p=0.022)$. Veleda et al. also suggested that infants who were identified as having retarded motor development using the motor development Denver test often have low-income mothers 
who attended the education classes for less than 6 sessions in health care centers. They often had multiple predisposing factors for their retarded growth [27].

Veleda et al. believes that regular maternal visits during pregnancy can affect infants' motor skills. Furthermore, he believes that infants with low-income families will face developmental delay. In general, according to the study reviews, wellbeing in the mood of pregnant mothers with lower cortisol levels who have effective communication with their babies can establish better motor development in their infant.

In other words, studies that have focused on anxiety as the main factor influencing the motor development index and infants' development have been highlighted. However, in studies that have only focused on prenatal visits and training in developmental skills could not prove their impact on infants' motor development.

Although this training is not futile regarding infants' motor development, more attention needs to be paid to anxiety control and mood improvement in pregnant mothers.

In other words, the effect of training on infant development outcomes can improve if it starts long before birth, with more focus on the quality of fetus-maternal interaction, mood improvement, and anxiety and depression reduction in mothers.

Due to time constriction in the present study, implementing an emotional attachment training program is recommended from the beginning of pregnancy for couples in further research. In addition, evaluation of infants' motor development is suggested in the first two years of life.

The limitation of this study was the inability to use men (husbands) in meetings due to the lack of participation of some of them. Also, the implementation of this intervention was in the hospital. If the training is conducted outside the hospital, the likely effectiveness could be higher. Besides, if training runs from the beginning of pregnancy, or at least the beginning of the second quarter, greater opportunities for practical education would be created.

\section{Conclusions}

In the intervention group, training in attachment behaviors led to a significant decrease in the achievement age of infants in a few items of gross motor skills. This change was significant in all cases of Speech-Language skills and one item of fine-adaptive motor development. In addition, this difference was significant in some cases of personal-social skills and some gross-fine movements at one month and three months. Since attachment behaviours and fetus-maternal interaction are important, the role of the midwife as a guide for mothers cannot be ignored in alerting women during pregnancy. This education will lead to health improvements for both mother and infants at minimal expense.

Acknowledgements. The present article was extracted from the thesis of Akram Dokuhaki (thesis number: 926857, IRCT: 2014042217393N1). The authors would like to thank the Research Vice-chancellor of Shiraz University of Medical Sciences for financially supporting the study. The authors would like to thank Dr. Nasrin Shokrpour at the Center for the Development of Clinical Research of Nemazee Hospital for editorial assistance.

Source of funding: This work was funded by the Shiraz University of Medical Sciences.

Conflicts of interest: The authors declare no conflicts of interest.

\section{Refrences}

1. Oppenheim D, Koren-Karie N, Sagi-Schwartz A. Emotion dialogues between mothers and children at 4.5 and 7.5 years: relations with children's attachment at 1 year. Child Dev 2007; 78(1): 38-52.

2. Jeanne L, Alhusen RN. A literature update on maternal-fetal attachment. J Obstet Gynecol Neonatal Nurs 2008; 37(3): 315-328.

3. Nelson LJ, Fazio AF. Emotional content of talk to the fetus and healthy coping behaviors during pregnancy. Infant Mental Health J 1995; 16(3): 179-191.

4. Akbarzadeh $\mathrm{M}$, Rafiee $\mathrm{B}$, Asadi $\mathrm{N}$, et al. Comparison of two methods of relaxation and maternal-fetal attachment on the fetal heart pattern. Nautilus 2014; 128(1): 104-112.

5. Toosi M, Akbarzadeh M, Zare N, et al. Effect of attachment training on anxiety and attachment behaviors of first-time mothers. Hayat 2011; 17(3): 69-79 (in Persian).

6. Babaei N. Health needs of children in the context of social change. Social Werfare 2003; 2(7): 49-58 (in Persian).

7. Alhusen JL, Hayat MJ, Gross D. A longitudinal study of maternal attachment and infant developmental outcomes. Arch Womens Ment Health 2013; 16(6): 521-529.

8. Riva Crugnola C, Gazzotti S, Spinelli M, et al. Maternal attachment influences mother-infant styles of regulation and play with objects at nine months. Attach Hum Dev 2013; 15(2): 107-131.

9. Maldonado-Duran JM, Lartigue T, Feintuch M. Perinatal psychiatry: infant mental health interventions during pregnancy. Bull Menninger Clin 2000; 64(3): 317-343.

10. Alhusen JL, Gross D, Hayat MJ, et al. The influence of maternal-fetal attachment and health practices on neonatal outcomes in lowincome, urban women. Res Nurs Health 2012; 35(2): 112-120.

11. Brumariu LE, Kerns KA, Seibert A. Mother-child attachment, emotion regulation, and anxiety symptoms in middle childhood. Pers Relatsh 2012; 19(3): 569-585.

12. Burgess KB, Marshall PJ, Rubin KH, et al. Infant attachment and temperament as predictors of subsequent externalizing problems and cardiac physiology. J Child Psychol Psychiatry 2003; 44(6): 819-831.

13. Akbarzadeh M, Dokuhaki A, Joker A, et al. Teaching attachment behaviors to pregnant women: a randomized controlled trial of effects on infant mental health from birth to the age of three months. Annals of Saudi Medicine 2015; 36(3): 175-183.

14. Steenweg-de Graaff J, Tiemeier H, Steegers-Theunissen RP, et al. Maternal dietary patterns during pregnancy and child internalising and externalising problems. The Generation R Study. Clinical Nutrition 2014; 33(1): 115-121.

15. Donovan EL. Getting mothers moving: maternal exercise during pregnancy and long-term offspring health benefits. Exerc Sport Sci Rev 2015; 43(4): 179-180.

16. Perales M, Santos-Lozano A, Ruiz JR, et al. Benefits of aerobic or resistance training during pregnancy on maternal health and perinatal outcomes: a systematic review. Early Hum Dev 2016; 94: 43-48.

17. Aghamohammadiyan HR, Roshan R, Zamani Z, et al. Developmental psychology. Tehran: Misagh Publications; 1996.

18. Tubach F, Greacen T, Saias T, et al. A home-visiting intervention targeting determinants of infant mental health: the study protocol for the CAPEDP randomized controlled trial in France. BMC Public Health 2012; 12: 648. 
19. Toosi M, Akbarzadeh M, Zare N, et al. The role of relaxation training in health index of infants in pregnant mothers. Journal of Jahrom University of Medical Sciences 2013; 11(1): 14 (in Persian).

20. Muluk NB, Bayoğlu B, Anlar B. Language development and affecting factors in 3-to 6-year-old children. Eur Arch Otorhinolaryngol 2014; 271(5): 871-878.

21. Figueiredo B, Pinto TM, Pacheco A, et al. Fetal heart rate variability mediates prenatal depression effects on neonatal neurobehavioral maturity. Biol Psychol 2016; 28: S0301-0511(16)30315-5.

22. Bergman K, Sarkar P, Glover V, et al. Maternal prenatal cortisol and infant cognitive development: moderation by infant-mother attachment. Biol Psychiatry 2010; 67(11): 1026-1032.

23. Cho J, Holditch-Davis D. Effects of perinatal testosterone on infant health, mother-infant interactions, and infant development. Biol Res Nurs 2013: 1099800413486340.

24. O'Connor TG, Monk C, Fitelson EM. Practitioner review: maternal mood in pregnancy and child development-implications for child psychology and psychiatry. J Child Psychol Psychiatry 2014; 55(2): 99-111.

25. Alidustishahraki K, Hosseininasab A, Foruhari S. Effects of mothers' training about complementary feeding and developmental skills on growth and development of 5-7 month infants referring to health centers in Shiraz, 2003. Hakim Research Journal 2008; 11(2): 33-38 (in Persian).

26. Burchinal MR, Roberts JE, Nabors LA, et al. Quality of center child care and infant cognitive and language development. Child Dev 1996; 67(2): 606-620.

27. Veleda AA, Soares M, Cézar-Vaz MR. Fatores associados ao atraso no desenvolvimento em crianças, Rio Grande, Rio Grande do Sul, Brasil. Revista Gaúcha de Enfermagem 2011; 32: 79-85.

Tables: 6

Figures: 2

References: 27

Received: 29.11.2016

Revised: 10.01.2017

Accepted: 10.01.2017

Address for correspondence:

Marzieh Akbarzadeh, MSc

Maternal - Fetal Medicine Research Center

Department of Midwifery

School of Nursing and Midwifery

Shiraz University of Medical Sciences

Shiraz

Iran

Tel.: 0711-6474250

E-mail: akbarzadm@sums.ac.ir 